\section{Linfoma anaplásico de células grandes asociado a implantes mamarios. Cuatro casos dilagnosticados en la provincia de Alicante, España}

\section{Breast implant associated anaplastic large cell lymphoma. Four cases diagnosed in the province of Alicante, Spain}

\author{
Mauricio UMAÑA ORDÓÑEZ*, César A. RECALDE LOSADA**, Raquel RUBIO VERDÚ*** \\ Francisco SOLESIO PILARTE ${ }^{\star \star \star \star}$, Gloria PEIRO CABRERA ${ }^{\star \star \star *}$, Elena LORDA BARRAGUER ${ }^{\star \star \star \star \star \star}$
}

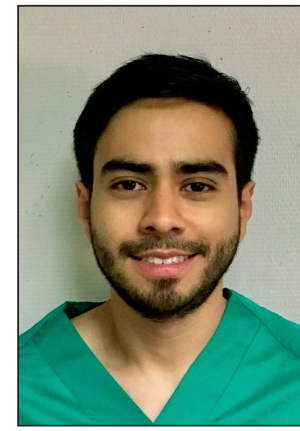

Umaña Ordóñez M.

\section{Resumen}

Abstract
Introducción y Objetivo. El linfoma anaplásico de células grandes asociado a implantes mamarios es un subtipo de linfoma de células T periférico que se puede encontrar en la cápsula periprotésica, el fluido entre implante y cápsula en forma de seroma o en casos avanzados como enfermedad metastásica.

Aportamos 4 casos clínicos de este tipo de linfoma diagnosticados en la provincia de Alicante, España, siendo de interés por ser escasa la incidencia reportada y pocos los trabajos científicos

Material y método. Describimos estos 4 casos registrando: edad, antecedentes, indicación del implante, detalles de la cirugía previa, tipo de superficie y marca del implante, presentación clínica del cuadro y tratamiento administrado.

Resultados. Dos casos correspondieron a cirugía estética y 2 a cirugía reconstructiva, la presentación clínica en 3 casos fue como seroma tardío y en 1 como linfadenopatía. Tres implantes eran de superficie texturizada y 1 de poliuretano. En todos los casos se realizó capsulectomía bilateral.

Conclusiones. La aportación de nuestra serie contribuye a destacar la importancia de reportar los casos diagnosticados dada la escasa incidencia de la enfermedad y el reducido número de publicaciones sobre la misma en el ámbito iberolatinoamericano. publicados a nivel nacional sobre esta patología.
Background and Objective. The anaplastic large cell lymphoma associated with breast implants is a subtype of peripheral T cell lymphoma that can be found in the periprosthetic capsule, the fluid between the implant and the capsule in the form of a seroma, or in advanced cases such as metastatic disease.

We provide 4 clinical cases diagnosed in the province of Alicante, Spain, being of interest because of the low incidence reported and few published scientific papers nationwide.

Methods. We describe these 4 clinical cases and recorded: age, history, implant indication, previous surgery details, implant type of surface and brand, clinical presentation of the pathology and treatment.

Results. Two cases corresponded to cosmetic surgery and 2 to reconstructive surgery; clinical presentation in 3 cases was late seroma and lymphadenopathy in 1 . Three implants had textured surface and one was of polyurethane. Bilateral capsulectomy was performed in all cases.

Conclusions. The main contribution of our cases is to highlight the importance of informing about diagnosed cases, because of the rare incidence of the disease and the lack of publications about this theme in the Ibero-Latinamerican environment.
Palabras clave Implante mamario, Prótesis mamarias, Linfoma anaplásico de células grandes

\section{Nivel de evidencia científica Recibido [esta versión] Aceptado}

\section{5c Diagnóstico \\ 15 mayo/2019 \\ 13 agosto/2019}

\section{Key words Breast Implant, Breast prosthesis, Anaplastic large cell lymphoma}

\section{Level of evidence Received [this version] Accepted}

5 c Diagnostic 15 May/2019

13 Augost/2019
Conflicto de intereses: Los autores declaran no tener ningún interés financiero relacionado con el contenido de este artículo.

Financiación: No hubo fuentes externas de financiación para este trabajo.

\footnotetext{
Médico Residente, Servicio de Cirugía Plástica Hospital General Universitario de Alicante, Alicante, España

** Médico Adjunto, Servicio de Cirugía Plástica Hospital General Universitario de Alicante, Alicante, España

*** Médico Adjunto, Servicio de Cirugía Plástica Hospital General Universitario de Elche, Alicante, España

**** Médico Adjunto, Servicio de Anatomía Patológica Hospital General Universitario de Alicante, Alicante, España

***** Jefe de Sección, Servicio de Cirugía Plástica Hospital General Universitario de Elche, Alicante, España

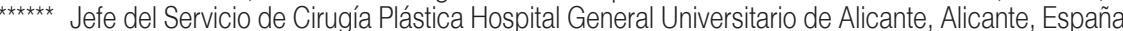


El linfoma anaplásico de células grandes asociado a implantes mamarios (LACG-IM) es un subtipo de linfoma de células $\mathrm{T}$ periférico que se puede encontrar en la cápsula periprotésica, el fluido entre el implante y la cápsula en forma de seroma o en casos avanzados como enfermedad metastásica. ${ }^{(1)}$ En 2016 fue incluido por la Organización Mundial de la Salud (OMS) como una entidad provisional en la clasificación de los linfomas para distinguirlo de otras neoplasias de células T. ${ }^{(2)}$

No se trata de una patología nueva ya que fue descrito por primera vez en $1997,{ }^{(3)}$ pero es a partir del año 2011 cuando toma mayor importancia tras emitirse un comunicado de seguridad por parte de la Food and Drug Administration (FDA) en EE.UU. sobre su posible asociación a implantes mamarios. ${ }^{(4)}$ Desde entonces el número de casos descritos mundialmente ha ido en aumento, hasta un total de 660 en los últimos datos publicados al momento de la redacción de este trabajo, ${ }^{(5)}$ permitiendo mejorar los conocimientos acerca de esta rara patología.

En España son pocas las publicaciones relacionadas con este tema, ${ }^{(6-8)}$ y no existen datos epidemiológicos publicados al respecto. En esta misma revista pudimos leer también el primer caso publicado desde México y Latinoamérica. ${ }^{(9)}$

En este trabajo presentamos 4 casos clínicos de LACG-IM confirmados en la provincia de Alicante, España: 2 pacientes intervenidas en su día para colocación de implantes mamarios por motivos estéticos y 2 por reconstrucción mamaria. Con ello, pretendemos promover y aumentar la sospecha de esta patología entre nuestros colegas mediante un mejor entendimiento de la misma, a la vez que incentivar la publicación de otros casos diagnosticados en el resto de hospitales nacionales y de nuestro ámbito iberolatinoamericano, en el que las referencias al respecto son muy limitadas.

\section{Material y Método}

Presentamos una revisión retrospectiva de 4 casos de LACM-IM diagnosticados en hospitales de la provincia de Alicante (España), 3 en el Hospital General Universitario de Elche y 1 en el Hospital General Universitario de Alicante. Registramos en todos ellos los datos de: edad, antecedentes de interés, indicación del implante mamario, detalles de la cirugía o cirugías realizadas, tipo de superficie y marca del implante, presentación clínica del cuadro de linfoma y tratamiento recibido por las pacientes.
Caso 1. Mujer de 40 años de edad, de raza blanca, $\sin$ antecedentes médicos de interés. Fue intervenida por aumento mamario estético en octubre de 2007 en un hospital privado, colocándosele prótesis marca Inamed ${ }^{\circledR}$ (Inamed Aesthetics, Santa Bárbara, California, EE.UU.) de gel cohesivo de silicona, anatómicas, texturizadas, de 245 cc., estilo MM. Durante el postoperatorio inmediato presentó un pequeño seroma en la mama izquierda que fue drenado sin incidencias.

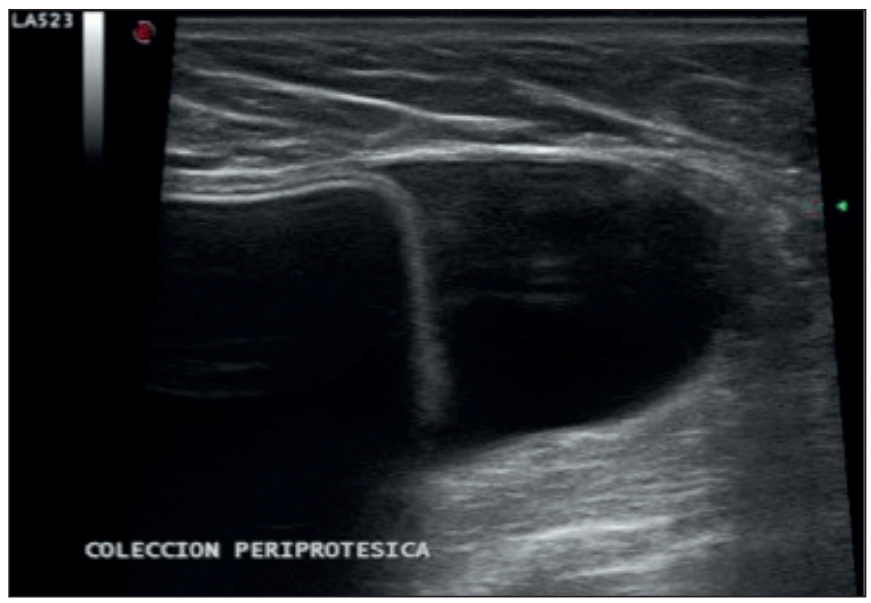

Fig.1. Caso 1. Ecografía de mama izquierda. Colección periprotésica en cuadrante ínfero-externo de aproximadamente $25 \mathrm{~mm}$ de grosor.

En octubre de 2011, 4 años después de la primera intervención, la paciente acude a consulta de su hospital privado por presentar asimetría mamaria. La valoración ecográfica informó de la existencia de rotura bilateral de los implantes y seroma en la mama izquierda (Fig. 1). Se solicitó resonancia magnética (RM) que confirmó el seroma de la mama izquierda y descartó la rotura de las prótesis. Adicionalmente se realizó una punción aspiración con aguja fina (PAAF) guiada por ecografía, drenándose $560 \mathrm{ml}$ de líquido seroso del que se enviaron muestras para cultivo y citología convencionales, con resultados negativos.

La paciente presentó una evolución favorable, pero 7 meses después acude de nuevo por presentar un seroma en la mama izquierda que se confirmó por estudios de imagen. Tras los hallazgos descritos y ante la clínica de seroma recidivante se procedió a intervención quirúrgica realizando capsulectomía completa y recambio por prótesis Inamed ${ }^{\circledR}$, de gel cohesivo de silicona, de similares características a las previas. Se remitieron muestras para cultivo y estudio citológico y la cápsula para estudio histológico. El material citológico demostró la presencia de una población celular linfoide de predominio de células grandes con núcleo atípico y abundantes figuras de mitosis. Sin embargo, en el material histológico la representación linfoide maligna viable fue muy escasa, identificán- 
dose de manera muy focal pequeños grupos de células en un tejido predominantemente fibrino-hialino y necrótico. El estudio inmunohistoquímico demostró positividad para CD3 y CD30 y negatividad para CD20 y ALK, siendo la actividad proliferativa con Ki67 alta (90\%), datos compatibles con diagnóstico de linfoma no Hodgkin de células grandes anaplásico/ALK-negativo asociado a implante mamario (LACG-IM). El estudio microbiológico fue negativo así como el estudio de extensión.

Por decisión de los comités de patología mamaria y de linfomas, la paciente no recibió otro tipo de tratamiento adicional. Hasta la actualidad sigue con controles periódicos por el Servicio de Oncología y se mantiene asintomática.

\section{Caso 2}

Mujer de raza blanca, de 47 años de edad, con antecedentes personales de linfoma de Hodgkin diagnosticado en 2016 estadio IV, tratado con quimioterapia con remisión completa de la enfermedad. Como antecedentes quirúrgicos, en el año 2006 fue operada en un centro privado para aumento mamario estético con prótesis Polytech $^{\circledR}$ (Polytech Health and Aesthetics, Alemania), aunque desconocemos la información de estos implantes ya que la paciente no la aporta y no fue posible acceder al historial clínico. En 2010 acude a consulta a su centro privado; aunque desconocemos la sintomatología inicial, el cirujano tratante sospechó rotura de los implantes, por lo que, en el mismo centro, se procedió a cirugía de recambio de los implantes mamarios por otros de la marca Allergan $^{\circledR}$ (Allergan Inc., Irvine, California, EE. UU.), redondas de gel de silicona cohesivo, texturizadas, Inspira TSX, de $285 \mathrm{cc}$. Durante la intervención queda descartada la rotura de los implantes previos.

En febrero de 2017, 7 años después de la última intervención quirúrgica, la paciente presenta endurecimiento de la mama izquierda sin otra sintomatología asociada, por lo que se solicitó RM que documentó capsulitis retráctil y seroma con captación de gadolinio. El estudio diagnóstico se complementó con una PAAF guiada por ecografía del seroma mamario izquierdo y se enviaron muestras para citología y cultivo del líquido, cuyos resultados fueron negativos. En octubre de 2017 la paciente fue sometida a una nueva intervención para recambio de implantes, en el mismo centro privado, colocándose en este momento prótesis de gel cohesivo de silicona marca Mentor ${ }^{\circledR}$ (Mentor Worldwide LLC, Santa Bárbara, California, EE.UU.), redondas, texturizadas, de 275 cc. Durante la intervención se tomó muestra del líquido periprotésico que fue enviada para estudio citológico, con resultado nuevamente negativo. Cuatro meses después de la última intervención acude nuevamente a

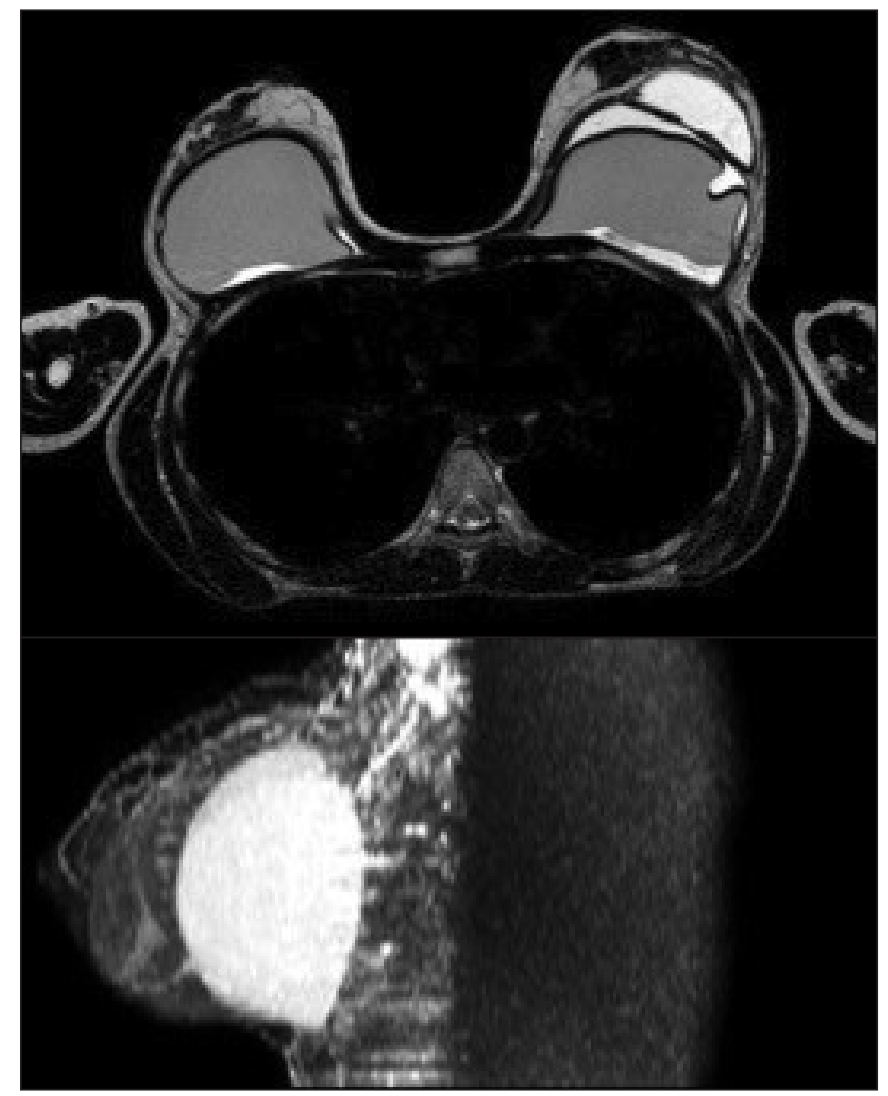

Fig. 2. Caso 2. Resonancia magnética, corte axial/T2/TSE y corte sagital silicone-only. Ligero engrosamiento de la cápsula izquierda que capta contraste de manera intensa, compatible con capsulitis retráctil. Seroma periprotésico izquierdo.

consulta por presentar recidiva del seroma en la mama izquierda, por lo que se solicitó una nueva RM que documentó capsulitis izquierda con colección periprotésica y siliconoma axilar izquierdo (Fig. 2). Al mes siguiente fue evaluada por el mismo seroma y se hizo una nueva PAAF de la colección líquida, obteniendo material serohemático con linfocitos que resultó insuficiente para el diagnóstico, pero debido a la clínica altamente sospechosa ya en este momento de LACG-IM, se decidió solicitar una biopsia en bloque celular del líquido obtenido. Los resultados fueron compatibles con LACG-IM y el estudio inmunohistoquímico demostró positividad para CD30, CD45 y marcadores de linfocitos T (CD43, CD3, CD4, CD5), y negatividad para ALK, CD15 y linfocitos $\mathrm{B}(\mathrm{CD} 20)$.

Tras este diagnóstico, la paciente fue remitida al Comité de Patología Mamaria del Hospital de Elche, que decidió retirada bilateral de los implantes con capsulectomía completa; las prótesis fueron extraídas de bolsillo retropectoral y se encontraron tabiques capsulares en el interior del bolsillo izquierdo con engrosamiento de la pared capsular.

En la actualidad, la paciente está en seguimiento por Oncología sin evidencia de enfermedad y con estudios de extensión negativos. No ha requerido tratamiento adicional. 


\section{Caso 3}

Mujer de 53 años de edad, raza blanca, con antecedentes de aumento mamario llevado a cabo en un centro privado en 2004; se desconocen los datos de los implantes utilizados ya que la paciente no aporta y no fue posible acceder al historial clínico. En 2010 desarrolla una masa en la mama izquierda, diagnosticada de carcinoma ductal infiltrante grado III con receptores de estrógenos (RE)/HER2-positivos (fenotipo luminal B/HER2-positivo), adenopatías axilares y supraclaviculares ipsilaterales. Fue tratada con mastectomía izquierda, vaciamiento axilar y exéresis de adenopatías supraclaviculares y recibió tratamiento adyuvante con radioterapia y hormonoterapia con tamoxifeno, con remisión de la enfermedad.

Transcurridos 2 años se sometió a reconstrucción mamaria izquierda con colgajo del dorsal ancho más expansor y mastopexia con prótesis retropectoral en la mama contralateral. La paciente no aporta datos sobre el expansor y el implante empleado en este momento y no fue posible acceder al historial clínico. En un segundo tiempo, se llevó a cabo en la mama izquierda capsulotomía con adaptación del bolsillo retromuscular y recambio del expansor mamario por prótesis definitiva, marca Silimed ${ }^{\circledR}$ (Silimed Industria de Implantes, Ltda., Brasil) de gel de silicona con revestimiento de poliuretaro, anatómica, de $435 \mathrm{cc}$. En la mama contralateral, tras el hallazgo de rotura de prótesis y contractura capsular, se procedió a realizar una nueva mastopexia, capsulectomía completa, retirada de la prótesis y recambio por implante marca Silimed $^{\circledast}$ de gel de silicona, texturizado, anatómico, de $325 \mathrm{cc}$.

En julio del 2018, 7 años después de la última intervención, la paciente acude al Hospital General Universitario de Alicante tras desarrollar un seroma en la

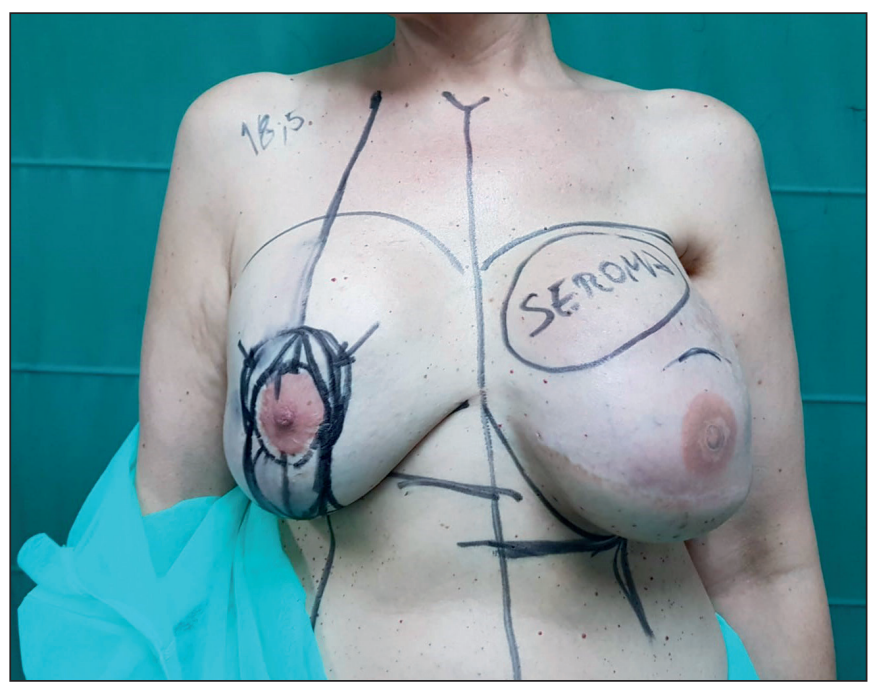

Fig. 3. Caso 3. Seroma periprótesico de la mama izquierda.

mama izquierda acompañado de eritema y leves cambios inflamatorios (Fig. 3). Se decidió drenar el líquido y se enviaron muestras para cultivo bacteriológico, cuyos resultados fueron negativos. Como persistía el seroma, se decidió llevar a cabo intervención quirúrgica para drenaje completo del seroma y recambio de la prótesis. Durante la cirugía se pudo comprobar que la cápsula periprotésica izquierda estaba engrosada (Fig. 4) y se enviaron muestras para cultivo y estudio anatomopatológico especificando realizar inmunohistoquímica CD-30, citología y descartar específicamente LACG-IM. Se retiraron los dos implantes, comprobando que eran diferentes: izquierda de poliuretano y derecha macrotexturizada. Por desestabilización hemodinámica de la paciente durante la intervención no se pudo completar la capsulectomía. De las muestras enviadas se obtuvieron resultados negativos para el cultivo pero en la inmunohistoquímica de la biopsia capsular izquierda se apoyó el diagnostico de LACG-IM tras observarse positividad para CD30, CD4,

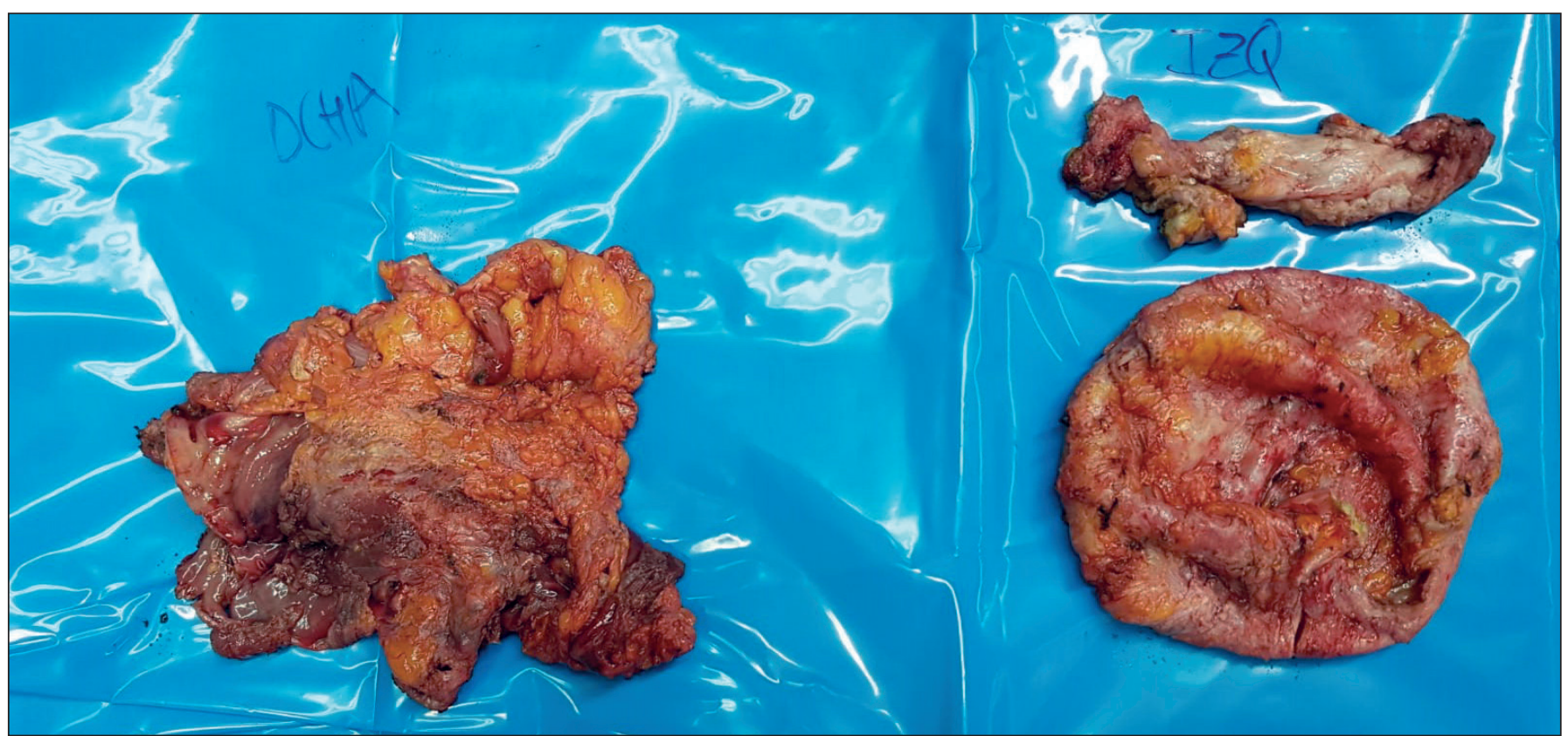

Fig. 4. Caso 3. Capsulectomía de ambas mamas. 


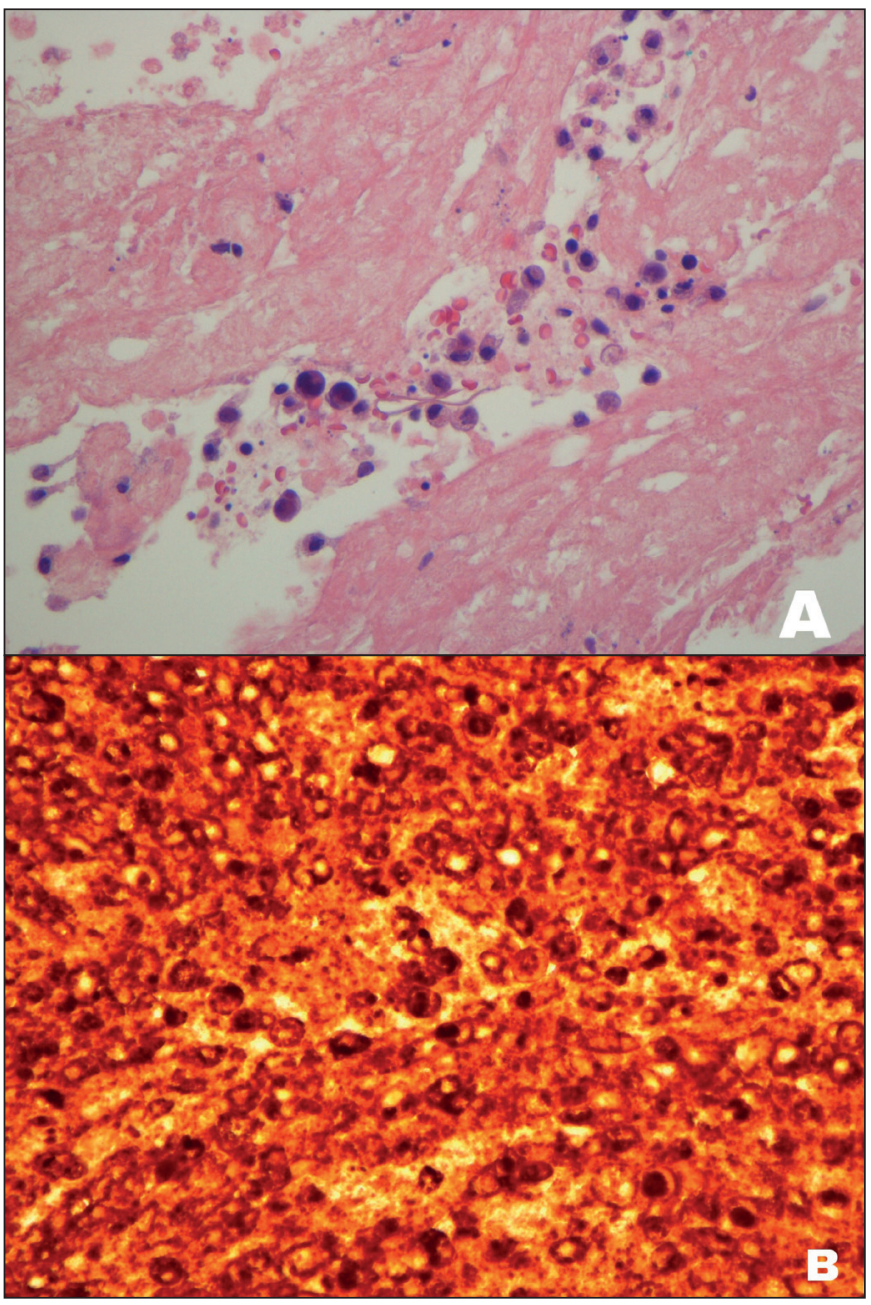

Fig. 5. Caso 3. Biopsia de la cápsula periprotésica izquierda con microscopio de gran aumento $(400 \mathrm{x})$ : A. Tinción de hematoxilina-eosina con escasa población celular linfoide atípica viable y abundante material fibrino-necrótico. B. El estudio con CD-30 demuestra positividad incluso en la población neoplásica necrótica.

CD5, CD43 y negatividad para CD2, CD3, CD7, CD8, BCL2, CD45 y ALK (Fig. 5). En la mama contralateral el estudio fue negativo.

La paciente fue informada del diagnóstico y se procedió a realizar nueva intervención quirúrgica para la capsulectomía completa. Posteriormente se presentó el caso en el Comité de Patología Mamaria del hospital y se remitió el caso al Servicio de Oncología.

En la actualidad, la paciente está libre de recidivas y tanto las biopsias enviadas en la última intervención como los estudios de extensión han sido negativos, por lo que no ha precisado tratamientos adicionales y se mantiene en seguimiento evolutivo.

\section{Caso 4}

Mujer de 78 años de edad, raza blanca, con antecedentes de carcinoma ductal infiltrante en la mama izquierda, estadio I, diagnosticado en 1991 y tratado con linfadenectomia axilar y radioterapia; melanoma en pierna izquierda diagnosticado en 1996 y adenocarcinoma de recto-sigma diagnosticado en 2013.
Fue sometida a reconstrucción mamaria izquierda diferida en el Hospital General Universitario de Alicante en 2010 mediante prótesis mamaria de gel de silicona subpectoral izquierda, redonda, texturizada, de $210 \mathrm{cc}$, marca $\mathrm{McGhan}^{\circledR}$ (Inamed Aesthetics, Santa Bárbara, California, EE.UU.), con simetrización de la mama contralateral mediante mastopexia y colocación de prótesis subpectoral marca McGhan ${ }^{\circledR}$ Style 110, redonda, texturizada, de $150 \mathrm{cc}$. La paciente continuó su seguimiento evolutivo en la Unidad de Patología Mamaria del Hospital de Elche.

En octubre de 2016 comienza con mastalgia en mama izquierda y es diagnosticada de contractura capsular grado III de Baker. A la paciente se le explicó este diagnóstico pero se negó a la intervención quirúrgica.

En abril de 2017, durante el seguimiento evolutivo programado en la Unidad de Patología Mamaria se le realizó tomografía axial computarizada (TAC) torácica que puso de manifiesto una adenomegalia retropectoral izquierda, con aumento de tamaño respecto a sus estudios previos. Este hallazgo se complementó con tomografía por emisión de positrones (PET-TAC) que informó de compatibilidad con malignidad de la lesión; adicionalmente se observó una adenopatía axilar derecha, también con sospecha de malignidad.

En junio de 2017 se tomó biopsia de la adenopatía axilar derecha, observándose en el estudio anatomopatológico la presencia de tejido linfoide con células sospechosas de malignidad, por lo que fue remitida al Comité de Mama que decidió indicar extirpación de la adenopatía con arpón y nodulectomía retropectoral izquierda. Durante el procedimiento la paciente sufrió un neumotórax como consecuencia de la colocación del arpón, por lo que en agosto de 2017 se llevó a cabo la extirparon quirúrgica de ambas adenopatías axilares derechas y del nódulo retropectoral, con resultados negativos para malignidad en el estudio anatomopatológico.

En diciembre de 2017 presentó empeoramiento clínico de la contractura capsular de la mama izquierda y signos de contractura en la prótesis contralateral (Fig. 6), por lo que en febrero de 2018 se practicó intervención quirúrgica con retirada de los implantes y capsulectomía completa bilateral, encontrando los implantes íntegros no se colocaron nuevas prótesis. En el estudio anatomopatológico de la mama izquierda se observó cápsula fibrosa con áreas de necrosis isquémica sin evidencia de neoplasia y reacción inflamatoria gigantocelular de tipo cuerpo extraño; en la mama derecha los resultados fueron negativos.

En diciembre de 2018, tras seguimiento evolutivo por adenocarcinoma de colon, se realizó TAC tóraco-abdómino-pélvico que halló 3 adenopatías en la axila derecha. 


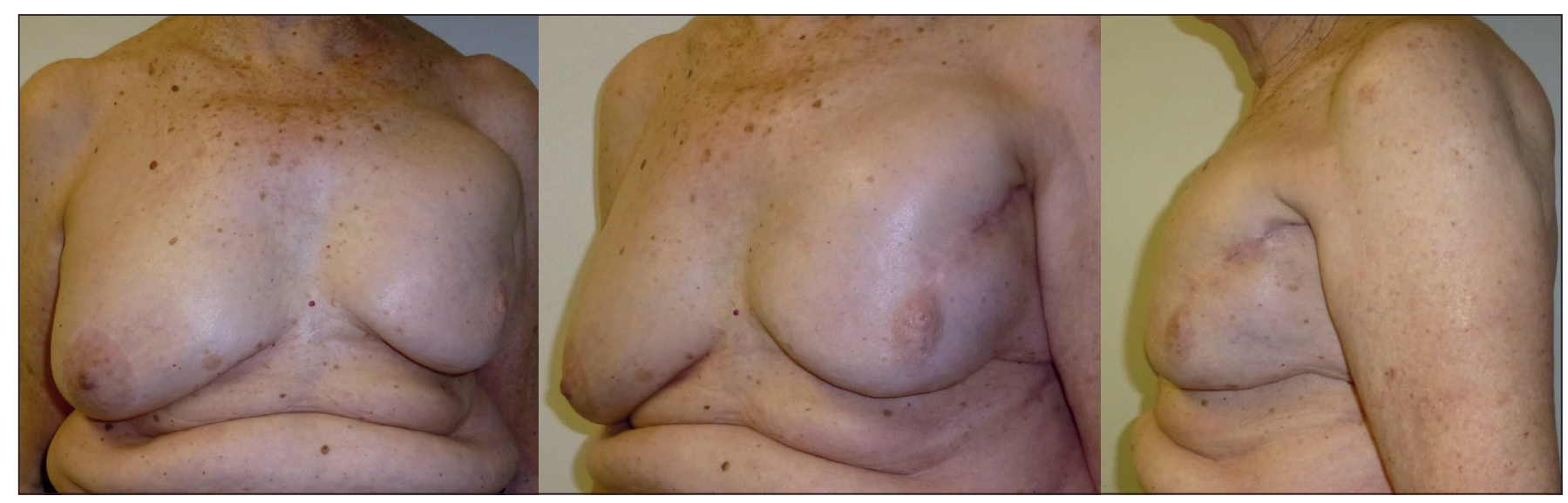

Fig. 6. Caso 4. Imágenes preoperatorias antes de la capsulectomía completa y retirada de ambas prótesis.

El Comité de Patología Mamaria decidió entonces realizar biopsia ecoguiada de las adenopatías, encontrando 2 axilares y 1 infraclavicular derecha y 1 axilar izquierda, con resultados positivos para linfoma anaplásico de células grandes, positivo para CD30, CD43, CD45 (LCA), BCL6 y EMA, y negativo para ALK, PAX-5, CD20, CD79, CD3, CD68, CD34 Y BCL2. Teniendo en cuenta los antecedentes de la paciente, se decidió practicar estudio inmunohistoquímico complementario de la cápsula mamaria izquierda obtenida en la intervención previa de febrero 2018, que estaba almacenada en el biobanco del hospital, encontrando células sueltas y pequeños cúmulos de células con inmunofenotipo superponible a las observadas en la última biopsia ganglionar, por lo que el diagnóstico final fue de LACG-IM. Se analizaron también las adenopatías axilares derechas, previamente biopsiadas en ese mismo hospital en 2017, con resultados negativos para linfoma.

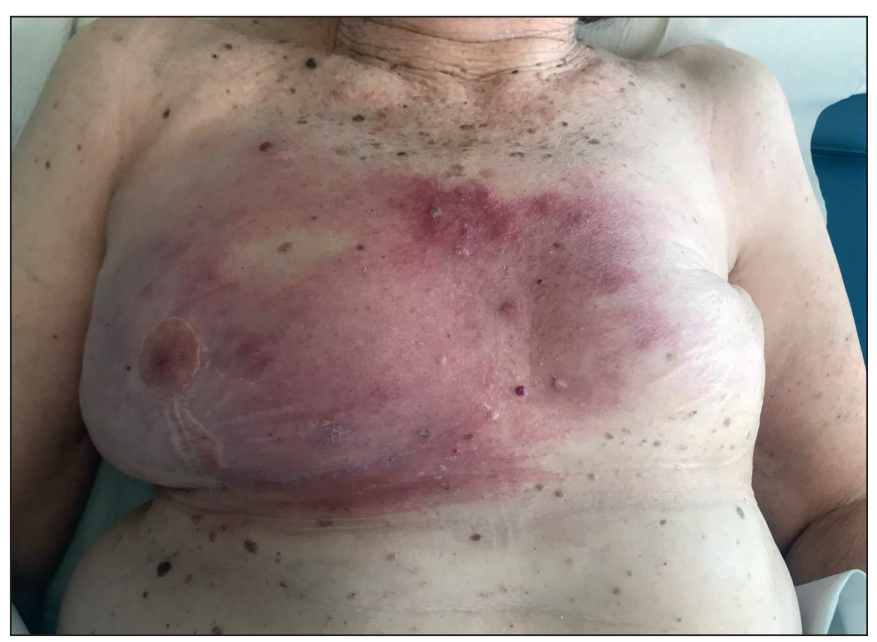

Fig. 7. Caso 4. Placa eritematosa que se extiende por ambas mamas.

En enero de 2019 la paciente presentó mastitis derecha, por lo que inició tratamiento con antibióticos orales. Ante el hallazgo clínico de una placa indurada inflamatoria que no mejoró con tratamiento antibiótico (Fig. 7), se tomó biopsia por sospecha de relación con el diagnóstico de LACG-IM. Los resultados revelaron que la inflamación de la mama derecha correspondía a infiltración cutánea del linfoma previamente diagnosticado.

En la actualidad la paciente se encuentra en tratamiento con quimioterapia (Ciclofosfamida, Doxurubicina y Prednisona) y Brentuximab Vedotin, en seguimiento por Oncología.

\section{Discusión}

El Hospital General Universitario de Alicante y el Hospital General Universitario de Elche son hospitales de atención terciaria pertenecientes a la red de hospitales de Sanidad Pública de la Comunidad Valenciana en España. Ambos hospitales son centros de referencia para patología o reconstrucción mamaria para distintas comarcas de la provincia de Alicante. Constan de unidades de patología mamaria con equipos multidisciplinares formados por ginecólogos, oncólogos, cirujanos generales y cirujanos plásticos.

La Comunidad Valenciana pertenece a las áreas geográficas más pobladas de España y consecuentemente, el número de cirugías mamarias que se realizan en ella es muy alto. El Hospital de Alicante y el de Elche en conjunto tienen asignado un $27.56 \%$ de la población de la comunidad (1.386.602 habitantes). ${ }^{(10)}$ Se trata por lo tanto de 2 hospitales que reciben la patología y las complicaciones de un gran número de cirugías mamarias.

El riesgo estimado de desarrollar LACG-IM según algunos autores está entre 1:3.800 mujeres $^{(11)}$ y 1: 30.000 mujeres con implantes mamarios texturizados, ${ }^{(12)}$ aunque Collett y col. consideran que este riesgo no se debe globalizar debido a las variaciones geográficas y étnicas reportadas. ${ }^{(13)}$ En nuestro medio, este riesgo es difícil de determinar pues no contamos con datos comparativos y hasta el momento no se habían reportado casos de LACG-IM en la provincia de Alicante, por lo que, hasta donde podemos saber, este trabajo representa la recopi- 
lación de todos los casos conocidos y confirmados en nuestra área geográfica, que hasta el momento de esta publicación son 4 en la provincia.

La presentación clínica habitual del LACG-IM es el seroma tardío, con una media de aparición de 8 años tras la intervención de colocación de los implantes mamarios. Las guías actuales de la National Comprehensive Cancer Network (NCCN) recomiendan descartarlo en toda mujer que presente líquido periprotésico 1 año después de la cirugía con implantes. ${ }^{(1,14)}$ En caso de que el seroma se presente antes del año desde la cirugía, no debe considerarse sospechoso ya que se encuentra fuera del espectro conocido de la enfermedad. ${ }^{(14)}$ En nuestras pacientes, la media de tiempo de inicio de los síntomas desde la cirugía fue de 4 años, siendo el caso 1 el de menor tiempo ( 5 años) y el caso 4 el de mayor tiempo (18 años).

En 2 de nuestras pacientes las citologías iniciales resultaron negativas en varias ocasiones, lo que ocasionó un retraso en el diagnóstico que consideramos puede ser atribuible a dos motivos:

1.- A la escasa densidad celular de las muestras y/o a la no sospecha de la neoplasia. Por ello, es importante reseñar la sospecha diagnóstica cuando se envían las muestras a estudio anatomopatológico y de laboratorio para que se descarte LACG-IM, realizando bloques celulares de las muestras citológicas del líquido y para que se lleven a cabo los estudios inmunohistoquímicos precisos (por ejemplo, CD30), así como remitir parte de la muestra para estudio por citometría de flujo y biopsia de la cápsula. Todo ello contribuirá a aumentar la probabilidad diagnóstica.

2.- La falta de orientación en el diagnóstico debido a que, hasta hace unos años, no se había desarrollado tanto interés y divulgación de la enfermedad, tal y como sucedió en nuestro caso 1, el más antiguo de nuestra serie, diagnosticado en 2011. En este momento aún no se habían publicado protocolos oficiales sobre el tratamiento de esta patología y existía únicamente un algoritmo diagnóstico publicado por Bengtson y col. sobre abordaje diagnóstico del seroma tardío. ${ }^{(15)}$

Por estas razones y en base a publicaciones recientes, ${ }^{(1,16,17)}$ en nuestros hospitales se ha establecido ya el empleo del protocolo diagnóstico recomendado por la Agencia Española del Medicamento y Productos Sanitarios (AEMPS) y por la Sociedad Española de Cirugía Plástica, Reparadora y Estética (SECPRE), y se ha mejorado la comunicación de estos casos entre distintos hospitales y especialidades a nivel de la provincia.

En la actualidad no se sabe cómo se desarrolla el LACG-IM, pero algunos autores consideran que podría estar relacionado con el tipo de superficie de los implantes mamarios así como con la formación de biolfilm. ${ }^{(18)}$
Otros autores sugieren junto a estas teorías la influencia como factor a tener en cuenta de la potencial predisposición individual relacionada con mutaciones en los genes JAK1 y STAT3. ${ }^{(19,20)}$ Para Oishi y col. existen diferencias genéticas que lo distinguen de otros subtipos de LACG. ${ }^{(21)}$ Wilkinson y col. consideran que, a mayor superficie de área del implante, mayor riesgo de que actúe como plataforma para el crecimiento y desarrollo de bacterias, que con el tiempo, inducen una respuesta y activación linfocitaria que puede ocasionar cambios en las células $\mathrm{T}$ de huéspedes susceptibles. Todo esto estaría especialmente incrementado en el caso de cubiertas Biocell ${ }^{\circledR}$ (Allergan, Dublin, Irlanda), que es la metodología patentada de macrotexturización de la marca de implantes de 3 de nuestros casos, o de poliuretano ${ }^{(22)}$ que corresponde a la cubierta del implante de nuestro caso 3 (Tabla I).

Sin embargo, creemos que afirmar que un tipo de marca de implantes pueda ocasionar mayor riesgo de LACG-IM puede ser una conclusión sesgada por diferentes motivos: muchas pacientes se someten a múltiples recambios de prótesis a lo largo de su vida sin que en todos los casos se pueda acceder luego a su historia clínica previa para conocer todos los tipos de marcas de implantes que han tenido; también parece claro que puede existir una preferencia por parte de los cirujanos para utilizar ciertas marcas de implantes con más asiduidad ${ }^{(23)} \mathrm{y}$, por lo tanto, generar más casos en esas marcas preferentemente más elegidas. Esto se vio reflejado en nuestro trabajo ya que no pudimos obtener información completa de todos los implantes utilizados por las pacientes en sus diferentes cirugías, ya fuera por pérdida de la documentación que les fue entregada en su momento, o falta de detalles de la información en sus historias clínica, o por proceder de otras instituciones hospitalarias sin que pudiéramos tener la posibilidad de acceder a sus historias clínicas completas.

También destacamos el caso 2, que se sometió a 2 recambios de prótesis. La paciente inicio con seroma periprotésico en el primer recambio, pero hasta el segundo no se logró diagnosticar la patología al ser más específicos en la sospecha diagnóstica y solicitar la biopsia en bloque celular del líquido periprotésico. Tomando en cuenta esto consideramos que pudo ser la prótesis utilizada en el primer recambio la que pudo ocasionar el LACG-IM, ya que fue la que inicio la sintomatología.

En cuanto al tratamiento, la cirugía con retirada de los implantes y capsulectomía completa bilateral constituye el tratamiento indicado. En nuestra serie, 3 de los casos fueron controlados quirúrgicamente siguiendo esta indicación, mientras que el caso 4 presentó recidivas a pesar de la cirugía, destacando que la paciente de este caso no tenía antecedentes de recambio de prótesis y que el inicio de la sintomatología fue el más tardío (a los 18 años). 
Tabla I. Características de los casos clínicos

\begin{tabular}{|c|c|c|c|c|}
\hline Caso & 1 & 2 & 3 & 4 \\
\hline Edad (años) & 40 & 47 & 53 & 78 \\
\hline $\begin{array}{l}\text { Indicación de la } \\
\text { cirugía inicial }\end{array}$ & Estética & Estética & Estética, Reconstructiva & Reconstructiva \\
\hline Lateralidad & Izquierda & Izquierda & Izquierda & Izquierda \\
\hline $\begin{array}{c}\text { Superficie del } \\
\text { implante* }\end{array}$ & Texturizado & Texturizado & Poliuretano & Texturizado \\
\hline Tipo de implante* & Gel cohesivo de silicona & Gel cohesivo de silicona & Gel cohesivo de silicona & Gel cohesivo de silicona \\
\hline $\begin{array}{l}\text { Marca del } \\
\text { implante* }\end{array}$ & Inamed $^{\circledR}$ & Allergan $^{\circledR}$ & Silimed $^{\circledR}$ & McGhan $^{\circledR}$ \\
\hline Clínica & Seroma tardío & Seroma tardío & Seroma tardío & Linfadenopatía \\
\hline $\begin{array}{l}\text { Tiempo desde la } \\
\text { última cirugía } \\
\text { al inicio de los } \\
\text { síntomas }\end{array}$ & 5 años & 7 años & 7 años & 18 años \\
\hline $\begin{array}{c}\text { Tiempo desde } \\
\text { el inicio de los } \\
\text { síntomas hasta el } \\
\text { diagnóstico }\end{array}$ & 8 meses & 13 meses & 2 meses & 12 meses \\
\hline $\begin{array}{l}\text { Tratamiento } \\
\text { quirúrgico }\end{array}$ & $\begin{array}{l}\text { Retirada de prótesis } \\
\text { Capsulectomía bilateral } \\
\text { Se colocó nuevo } \\
\text { implante }\end{array}$ & $\begin{array}{l}\text { Retirada de prótesis } \\
\text { Capsulectomía bilateral } \\
\text { No se colocó nuevo } \\
\text { implante }\end{array}$ & $\begin{array}{l}\text { Retirada de prótesis } \\
\text { Capsulectomía bilateral } \\
\text { No se colocó nuevo } \\
\text { implante }\end{array}$ & $\begin{array}{c}\text { Retirada de prótesis } \\
\text { Capsulectomía bilateral } \\
\text { No se colocó nuevo } \\
\text { implante }\end{array}$ \\
\hline $\begin{array}{c}\text { Tratamiento } \\
\text { complementario }\end{array}$ & No requirió & No requirió & No requirió & $\begin{array}{c}\text { Ciclofosfamida, } \\
\text { Doxurubicina, } \\
\text { Prednisona, } \\
\text { Brentuximab Vedotin }\end{array}$ \\
\hline $\begin{array}{c}\text { Número de } \\
\text { cirugías de } \\
\text { recambio previas }\end{array}$ & 0 & 2 & 1 & 0 \\
\hline
\end{tabular}

*Hace referencia al implante en el momento de la cirugía en la que se diagnóstico el LACG-IM

Se recomienda que la capsulectomía se realice de forma bilateral ${ }^{(24)}$ aunque la sintomatología de inicio, y por tanto de sospecha o diagnóstico de la enfermedad sea unilateral, ya que están documentado casos de enfermedad contralateral incidental. Por esta razón, en 3 de las pacientes de nuestra serie se decidió realizar retirada de los implantes y capsulectomía bilateral; en ningún caso encontramos enfermedad en la mama contralateral. En el caso 1, al ser el más antiguo tal y como hemos comentado anteriormente, se llevó a cabo recambio de los implantes por otros nuevos ya que aún la enfermedad no era de alta sospecha y no estaban definidos los protocolos diagnósticos ni terapéuticos, tal y como lo están en actualidad. Pero siguiendo también estos protocolos actuales, la paciente se mantiene en seguimiento sin indicación de retirar los nuevos implantes.

El LACG-IM no tiene siempre un curso indolente ya que están recogidos a nivel internacional casos de fallecimiento $^{(13)}$ que se cree pudieron estar ocasionados en su mayoría por retraso diagnóstico o terapéutico. En nuestra serie, 2 pacientes presentaron retraso de hasta 1 año para el diagnóstico: una corresponde al caso 2 que presentó evolución favorable tras la cirugía y otra al caso 4 que desarrolló recidiva de la enfermedad. En este último caso pudo influir también la falta de motivación de la paciente para operarse cuando fue informada del diagnóstico inicial y la falta de conocimiento sobre el diagnóstico exacto en la primera fase de la patología. De ahí la relevancia que a nuestro juicio tiene de la divulgación de toda la información disponible tanto a los profesionales sanitarios como a los pacientes, ya que esta patología, cuando es detectada en sus fases tempranas, suele tener un buen pronóstico.

Hasta la fecha no conocemos publicaciones acerca de la epidemiología de esta enfermedad en España y las referencias para su diagnóstico y tratamiento se basan en publicaciones de la literatura internacional, siendo muy pocos los casos clínicos publicados a nivel nacional. ${ }^{(6-8)}$ 
si bien alguna publicación anglosajona de $2019^{(13)}$ habla de 29 casos en España sin confirmar claramente la fuente de donde se obtuvo ese dato numérico, la AEMPS, hasta el momento de nuestra publicación, ha comunicado oficialmente haber recibido 36 sospechas de las cuales se han confirmado 26 casos, ${ }^{(17)}$ Por lo tanto, creemos que el presente trabajo es de interés para motivar la sospecha, el estudio y la caracterización de esta hasta el momento rara patología en nuestro país y también para incentivar la notificación de los casos recogidos a la autoridades sanitarias nacionales. Igualmente, para contribuir a la publicación científica sobre el tema en el ámbito iberolatinoamericano en el que como hemos mencionado con las citas pertinentes, son muy pocos los casos recogidos en la bibliografía.

\section{Conclusiones}

Nuestra serie de 4 casos de LACG-IM en la provincia de Alicante (España) contribuye a destacar la importancia de notificar a las autoridades sanitarias los casos diagnosticados dada la, hasta la fecha, poca incidencia de la enfermedad y el escaso número de publicaciones sobre el tema en el ámbito iberolatinoamericano.

El diagnóstico de LACG-IM se puede pasar por alto cuando no se tiene experiencia sobre la patología, por lo que debemos sospecharlo siempre ante la aparición de un seroma tardío o recidivante en pacientes con implantes mamarios, seguir los protocolos diagnósticos y terapéuticos establecidos y notificar el caso a las autoridades sanitarias correspondientes.

En los hospitales de referencia para un gran número de población debemos estar especialmente alerta, ya que muchos casos pueden no haber sido estrechamente seguidos en su evolución al haber sido intervenidos en diferentes centros. Como pudimos ver en los casos expuestos en este trabajo, es esencial la actualización constante de los protocolos hospitalarios para poder ofrecer el mejor tratamiento disponible en cada momento, pues el LACG-IM es una patología aún en estudio de la que se van obteniendo cada día nuevos conocimientos.

\section{Dirección del autor}

\author{
Dr. Mauricio Fernando Umaña Ordóñez \\ Servicio de Cirugía Plástica y Quemados \\ Hospital General Universitario de Alicante \\ C/ Pintor Baeza 11 \\ 03010, Alicante, España \\ Correo electrónico: mauricio_fu@hotmail.com
}

\section{Bibliografía}

1. Clemens MW, Jacobsen ED, Horwitz SM. NCCN Consensus Guidelines on the Diagnosis and Treatment of Breast Implant-Associated Anaplastic Large Cell Lymphoma (BIA-ALCL). Aesthet Surg J. 2019;39 (Supplement 1):S3-S13.

2. Swerdlow SA, Campo E, Pileri SA et al. The 2016 revision of the World Health Organization classification of lymphoid neoplasms. Blood 127(1528-0020 (Electrónico)):2375-2390.

3. Keech JA, Creech BJ. Anaplastic T-Cell Lymphoma in Proximity to a Salined Filled Breast Implant. Plast Reconstr Surg. 1997; 100:554-555.

4. U.S. Food and Drug Administration. Anaplastic large cell lymphoma (ALCL): Preliminary FDA findings and analyses. Disponible en: http://wayback.archive-it. org/7993/20171115053750/https:/www.fda.gov/MedicalDevices/ProductsandMedicalProcedures/ImplantsandProsthetics/ BreastImplants/ucm239996.htm Revisado el 10 de marzo del 2019.

5. American Society of Plastic Surgeons. Important notes about breast implant safety. Disponible en:https://www.plasticsurgery. org/Patient-safety/breast-implant-safety. Revisado el 10 de marzo del 2019

6. Tardio JC., Granados R. Axillary Lymphadenopathy: An Outstanding Presentation for Breast Implant-Associated ALK-Negative Anaplastic Large Cell Lymphoma. Int J Surg Pathol. 2015; 23(5):424-428.

7. Fernández-Sobrino I, Cordones-Guerrero JJ, Benítez-Dupin $\mathrm{O}$ et al. Masa palpable como presentación atípica de linfoma anaplásico de células gigantes asociado a implantes mamarios. Cir plást ilberolatinoam. 2017; 43(2):129-135.

8. Torres Olombrada M, García T, Caballero P et al. Anaplastic Large Cell Lymphoma associated with breast implant: A case report and review of the literature. Rep Oncol Radio. 2013;18:S275-S276.

9. Torres-Rivero C. Ramos-Gallardo G. Nambo-Lucio MJ y col. Primer caso en México y América Latina de linfoma anaplásico de células gigantes en paciente con implantes mamarios. Cir plást iberolatinoam. 2016, 42 (2):175-180.

10. Generalitat Valenciana. Data Warehouse: Ciudadanos Incluidos en el SIP, informe mensual. Comunidad Valenciana: Conselleria de Sanidad; 2019.

11. Clemens MW. BIA-ALCL Resources: by the numbers and what they mean. American Society of Plastic Surgeons. 2018. Disponible en:https://www.plasticsurgery.org/for-medical-professionals/health-policy/bia-alcl-physician-resources/by-thenumbers. Revisado en marzo del 2019.

12. Doren EL, Miranda RN, Selber JC et al. U.S. epidemiology of breast implant-associated anaplastic large cell lymphoma. Plast Reconstr Surg. 2017. 140:645-654.

13. Collett D, Rakhorst H, Lennox $P$ et al. Current Risk Estimate of Breast Implant-Associated Anaplastic Large Cell Lymphma in Textured Breast Implants. Plast Reconstr Surg. 2019. 143: 30S-40S.

14. Clemens MW, Brody GS, Mahabir RC et al. How to Diagnose and Treat Breast Implant-Associated Anaplastic Large Cell Lymphoma. Plast Reconstr Surg. 2018; 141: 586e-599e.

15. Bengtson B, Brody G F, Brown MH et al. Managing late periprosthetic fluid collections (seroma) in patients with breast implants: a consensus panel recommendation and review of the literature. Plast Reconstr Surg. 2011.128(1):1-7.

16. Di Napoli A. Achieving Reliable Diagnosis in Late Breast Implant Seromas: From Reactive to Anaplastic Large Cell Lymphoma. Plast Reconstr Surg. 2019;143(3S):15S-22S.

17. Agencia Española de Medicamentos y Productos Sanitarios AEMPS. Información sobre el Linfoma Anaplásico de Células Grandes Asociado a Implantes de Mama. Madrid: Editorial AEMPS; 2019. p. 1-4. 
18. Hu H, Johani K, Almatroudi A et al. Bacterial biofilm infection detected in breast implant-associated anaplastic large-cell lymphoma. Plast Reconstruc Surg. 2016; 137:1659-1669.

19. Blombery $\mathbf{P}$, Thompson ER, Jones $K$ et al. Whole exome sequencing reveals activating JAK1 and STAT3 mutations in breast implant-associated anaplastic large cell lymphoma. Haematol. 2016; e387-390.

20. Letourneau A, Maerevoet M, Milowich D. Dual JAK 1 and STAT3 mutations in a breast implant-associated anaplastic large cell lymphoma. Virchows Arch. 2018; 473: 505-511.

21. Oishi N, Brody G, Ketterling R. Genetic subtyping of breast implant-associated anaplastic large cell lymphoma. Blood. 2018; 544-547.
22. Loch- Wilkinson A, Beath K J, Knight RJW et al. Breast Implant-Associated Anaplastic Large Cell Lymphoma in Australia and New Zealand: High-Surface-Area Textured Implants Are Associated with Increased Risk. Plast Reconstr Surg. 2017; 140: 645-654.

23. Benito Ruiz J. Implantes mamarios en España: resultados de encuesta a cirujanos plásticos. Cir plást iberolatinoam. 2017:43:239-246.

24. Clemens MW, Medeiros LJ, Butler CE et al. Complete surgical excision is essential for the managemente of patients with breast implant-associated anaplastic large cell lymphoma. JPN J Clin Oncol. 2016. 34 (2):160-168. 